\title{
Aerobic Exercise and Endothelium
}

\author{
Allan Di Giaimo D'Almeida', Roberta Luksevicius Rica', Alexandre Lopes Evangelista², Ariana A. Silva', \\ Andrey Jorge Serra², Eliane F. Gama', Danilo Sales Bocalini'
}

\begin{abstract}
Background: A few years ago, it was believed that the endothelium was just a membrane separating blood from the outermost layers of blood vessels. However, it has now become recognized as a mediator of vasoconstricting and vasodilatory substances, regulating vessel tone through the information received. The main vasodilatory substance released by the endothelium is nitric oxide, a gas responsible for the inhibition of neovascular growth and platelet aggregation, modulating inflammation and coagulation, and can be released through physical and humoral stimuli. Exercise is considered the best non-pharmacological mechanism in the prevention and treatment of cardiovascular diseases, by promoting greater blood flow, generating blood shear forces on the vessel wall and thus releasing nitric oxide, the most important vasodilator produced by the endothelium. Objective: Verify the effects of aerobic exercise on the endothelium. Methods: We reviewed the studies that evaluated the effects of aerobic exercise and its intensities on the endothelium. Results: According to the studies reviewed in this research, impaired endothelial function improves through aerobic training, whether low, moderate or high intensity. Conclusion: Physical activity, specifically aerobic exercise is an important tool in the production of nitric oxide, responsible for blood vasodilation, inhibition of platelet aggregation among other symptoms of endothelial dysfunction.

Keywords: Endothelium, Nitric Oxide, Dysfunction, Aerobic Exercise, Intensity.
\end{abstract}

\section{INTRODUCTION}

The endothelium is characterized as an important sensory organ and has a privileged position in the control of cardiovascular health, commanding each part of the organism to the point of detecting the minimal changes of the same and send a global response in order to solve the problem. The endothelium is of extreme importance for the blood vessels, being responsible for maintaining vascular tone, fluidity of the plasma membrane, the balance between coagulation and fibrinolysis, besides controlling the inflammatory processes ${ }^{(1)}$. Among the functions of the endothelium, vasoconstriction and vasodilation of the blood vessels can be highlighted. As this is constantly assaulted by physical and chemical stresses its cells have varied defenses, which can be affected by diseases associated with the cardiovascular system ${ }^{(2)}$.

For a long time the endothelium was considered merely a barrier between the blood and the wall of tissues ${ }^{(3)}$. One of its main functions is the production of nitric oxide (NO), an important vasodilator, whose objective is to relax the smooth muscles of the vessels, causing an increase in blood flow ${ }^{(4)}$. However, inflammatory processes resulting from chronic diseases lead to endothelial dysfunction, which is characterized by impaired endothelial vasodilatation and is associated with a strong tendency for platelet aggregation, smooth muscle cell proliferation, leukocyte adhesion and, consequently, the development and progression of atherosclerosis ${ }^{(5)}$.

Cardiovascular risk factors such as overweight, obesity, smoking, and sedentary lifestyle influence endothelial dysfunction, leading to consequences such as reduction of vasodilator and antithrombotic responses, causing vascular damage and leading to a premature manifestation of atherosclerosis ${ }^{(2,6,7)}$.

Since the 1980s, it has been known that physical exercise can modify the vascular resistance, and neural control of the coronary circulation, and that they are considered protective by cardiovascular diseases, since among its many benefits is the release of nitric oxide ${ }^{(2)}$. However, as the literature is still controversial as to the intensity of physical exercise necessary to promote changes in the reestablishment of endothelial function, current research aims to verify which intensities are studied and what benefits are found for each intensity.

The most relevant original scientific articles, since 1991, were analyzed using the following search methods: Pubmed, Scielo, Google Scholar combining the keywords: endothelium, nitric oxide, endothelial dysfunction, exercise, intensity. Studies investigating the effects of exercise, as well as the

Correspondence: Allan Di Giaimo D'Almeida, Rua Silvia, 1603 ap. 41 ZIP code 09571-300, São Caetano do Sul, São Paulo, Brazil. personalallan@hotmail.com

${ }^{1}$ Universidade São Judas Tadeu (USJT), São Paulo (SP), Brazil.

Full list of author information is available at the end of the article.

Financial Support: nothing to declare.

Submission date 18 April 2017; Acceptance date 02 September 2017; Publication date 14 February 2018 
intensity used on the endothelium and the production of nitric oxide with or without endothelial dysfunction were considered as inclusion criteria, according Table 1.

\section{THE ENDOTHELIUM}

During the 1960s, it was believed that the endothelium was only an inert layer that had the function of covering the blood vessels. Lima et al. ${ }^{(3)}$ stated that for a long time it was considered merely a barrier between the blood and the wall of tissues. Bahia et al. ${ }^{(1)}$ point out that the endothelium separates the interstitium and the vascular wall of the blood, being organized by a continuous layer of spindle-shaped cells, and of extreme importance to the blood vessels, being responsible for maintaining the tonus vascular balance, fluidity of the plasma membrane, the balance between coagulation and fibrinolysis, as well as controlling inflammatory processes.

However, in the following decades, with a greater intensification in the studies, it was concluded that, when stimulated, the endothelium was able to produce the endothelium-derived relaxing factor (EDRF), a vasoactive substance ${ }^{(8)}$.

Characterized as the body's largest sensory organ, the endothelium can detect the slightest physiological changes and send a global response to the point of solving the problem, being fundamental in the relaxation of the arterial musculature, acting as a synthesizer and releasing substances with vasoactive actions, allowing the transport of macromolecules from the blood into the interstitial space ${ }^{(9,10)}$.
On the endothelial cells, they have an organic structure of extreme metabolic activity, having as its structural features the elongated form with a prominent nucleous and intracellular organelles $^{(6)}$.

It is known that such cells are responsible for the production of vasodilator substances, which are: Endothelium-derived relaxing factor (FRDE), known as nitric oxide (NO); acetylcholine, bradykinin, prostacyclin (PGI2), a potent antiplatelet agent; and the endothelium-derived hyperpolarizing factor (FHDE). On the other hand, these cells can also produce vasoconstricting substances, and growth promoters, because they stimulate the proliferation of vascular smooth muscle cells (VSMC). These substances are angiotensin II, endothelin 1 (ET-1), thromboxane $\mathrm{A} 2$ and prostaglandin $\mathrm{A} 2^{(6)}$.

\section{NITRIC OXIDE (NO)}

The discovery of this important vasodilator yielded the three pharmacologists Robert F. Furchgott, Louis J. Iguarro and Ferid Murad the Nobel Prize in Physiology or Medicine in $1998^{(8)}$. Nitric oxide is the most important vasodilator produced by the endothelium. After a shear stress (force of blood flow against the vessel wall), the endothelial cells activate the potassium channels, increasing the entry of calcium in the cells and thus, hyperpolarizing the endothelium. Consequently, the endothelial (eNOS) is activated by calcium releasing nitric oxide in order to relax vascular smooth muscle and reestablish homeostasis $^{(11)}$.

Table 1. Influence of aerobic physical exercise on endothelial function

\begin{tabular}{|c|c|c|c|c|c|}
\hline Author & Modality & Intensity & $\begin{array}{c}\text { Weekly } \\
\text { frequency }\end{array}$ & $\begin{array}{l}\text { Duration } \\
\text { (weeks) }\end{array}$ & $\begin{array}{l}\text { Endothelial } \\
\text { Function }\end{array}$ \\
\hline $\begin{array}{c}\text { Goto e cols., } \\
2003\end{array}$ & Exercise Bycicle & $\begin{array}{l}\text { Moderate } \\
50 \% \mathrm{VO}^{2 \max }\end{array}$ & 5 a 7 sessions & 12 & $\uparrow$ \\
\hline $\begin{array}{l}\text { Silva, } \\
2006\end{array}$ & Walking and/or running & High 75 to $85 \%$ FC Máx & 4 sessions & 6 & $\uparrow$ \\
\hline Feairheller e cols., 2014 & Aerobic Training (not specified) & Moderate 50 to $65 \% \mathrm{VO}^{2 \mathrm{Max}}$ & 3 sessions & 24 & $\uparrow$ \\
\hline Marioranna e cols., 2000 & Circuit (aerobic and strength training) & Moderate & 3 sessions & 8 & $\uparrow$ \\
\hline Bergholm e cols., 1999 & Running & High 70 to $80 \% \mathrm{VO}^{2 \mathrm{Max}}$ & 4 sessions & 12 & $\downarrow$ \\
\hline $\begin{array}{l}\text { Da Veiga, } \\
2008\end{array}$ & Water aerobics & Moderate 50 to $80 \% \mathrm{FC}$ & 3 sessions & 12 & $\begin{array}{l}\text { No-significant } \\
\text { alterations }\end{array}$ \\
\hline Clarkson e cols., 1999 & Running and strength training MMSS & Moderate & No informed & 10 & $\uparrow$ \\
\hline $\begin{array}{l}\text { Silva e cols., } \\
2016\end{array}$ & $\begin{array}{c}\text { Running } \\
\text { (animal model) }\end{array}$ & Moderate $60 \%$ Maximum speed & 5 sessions & 8 & $\uparrow$ \\
\hline $\begin{array}{l}\text { Kelly e cols., } \\
2004\end{array}$ & Exercise bycicle & Moderate-high 50 to $80 \% V^{2 M a ́ x}$ & 4 sessions & 8 & $\uparrow$ \\
\hline $\begin{array}{c}\text { Hornig e cols., } \\
1996\end{array}$ & Handgrip & Moderate & 7 sessions & 4 & $\uparrow$ \\
\hline $\begin{array}{l}\text { Hamdy e cols., } \\
2003\end{array}$ & $\begin{array}{c}\text { Modalities which move } \\
\text { MMSS e MMII }\end{array}$ & Moderate 60 to $80 \% \mathrm{FC}^{\mathrm{Max}}$ & 3 sessions & 24 & $\uparrow$ \\
\hline $\begin{array}{c}\text { Silva e cols., } \\
2016\end{array}$ & Walking and/or running & High 75 to $85 \%$ FCMax & 4 sessions & 6 & $\uparrow$ \\
\hline
\end{tabular}


The release of nitric oxide is modulated by physical and humoral stimuli. Physical stimuli include transmural hydrostatic pressure, circunferential stretching and shear stress produced by the friction of blood flow to the vessel wall, which is considered to be the main factor releasing NO. As for the humoral (endogenous) stimuli, we can mention some circulating hormones, such as: catecholamines, vasopressin, bradykinin, histamine and mediators released by platelets, these being ADP (adenosine diphosphate), serotonin, besides thrombin, which is formed during the coagulation ${ }^{(12)}$. According to Thompson ${ }^{(13)}$, NO activity in large diameter arteries seems to be maximal because of the large blood flow and shear forces. When increased blood flow occurs, calcium-dependent potassium channels, which are sensitive to shear, act as mechanochemical receptors, which promote NO release.

Cabral et al. ${ }^{(14)}$ complement that endothelial cells have channels of membrane ions, such as calcium and potassium, which respond to shear stress releasing nitric oxide in the amount proportional to the velocity of blood flow. NO is responsible for $70 \%$ of vasodilation, being formed from the enzyme endothelial nitric oxide synthase (eNOS) which converts the substrates oxygen and L-arginine to nitric oxide and L-citrulline ${ }^{(1,14)}$. Dias et al. ${ }^{(8)}$ complement that it is a gaseous molecule, presenting as a free radical, since in its structural form it presents an unpaired electron in the last layer and a half-life of 4 to 8 seconds in oxygenated aqueous medium. In addition to the vasodilatory effect, endothelium-derived nitric oxide exerts other functions on the blood vessels, such as inhibition of platelet aggregation, control of cell proliferation, inhibition of smooth muscle cell mitosis, regulation of leukocyte adhesion, and reduction of adhesion molecule expression and, moreover, can act as an antioxidant through its reaction with lipid peroxides ${ }^{(15)}$. Continuous endothelial NO production is involved in the maintenance of blood pressure, since inhibitors of the synthesis of this oxide, such as $\mathrm{N}$-monomethyl L-arginine (LNMMA), cause hypertension and vasoconstriction ${ }^{(13)}$. In the presence of classic risk factors, such as hypertension, diabetes mellitus, hypercholesterolemia and smoking, as well as emerging risk factors such as homocysteine, C-reactive protein (CRP) and lipoproteins (a), endothelium, through stress oxidative, releases or nitric oxide.

\section{ENDOTHELIAL DISFUNCTION}

Endothelial damage may be linked to several risk factors, such as advanced age, heart failure, hypertension, obesity, hypercholesterolemia, diabetes, smoking, sedentary lifestyle, free radicals, among others, resulting in alterations in vessel homeostasis, leading to a reduced vasodilation dependent endothelium, vascular hyper reactivity (vessel spasms), increased local cell adhesion, thrombus formation and vessel occlusion $^{(14,16)}$. It has been implicated in the pathogenesis of diabetic vascular disease and metabolic syndrome, as well as in low insulin sensitivity, dyslipidemia, hypertension, and also among active and passive smokers, leading to a common final pathway to cardiovascular diseases ${ }^{(17)}$. Endothelial dysfunction appears early in the progression of atherosclerosis, in which endothelial cells are the first to be exposed to inflammatory processes and disease, and consequently can lead to changes in vascular tone, thrombotic dysfunctions, proliferation and migration of smooth muscle cells (CML) and leukocyte adhesion, besides producing reactive oxygen species (ROS), which are responsible for reducing the bioavailability of nitric oxide $^{(1,14,18)}$.

Cabral et al. ${ }^{(14)}$ add that endothelial cell damage, potentiates the release of endothelin-1, a pro-inflammatory peptide and potent vasoconstrictor of large and small vessels. Endothelium function can be evaluated in a variety of ways through invasive or non-invasive methods, which may involve venous or arterial endothelium. Measurements can be made through examinations such as: Angiography, positron emission tomography, intracoronary Doppler, plethysmography, brachial artery ultrasound, carotid ultrasound with intima-media index, hand dorsal vein technique, velocity pulse wave, vessel lumen plethysmography, myocardium for small vessels of the subcutaneous and digital laser doppler ${ }^{(19)}$.

\section{AEROBIC EXERCISE AND ENDOTHELIUM}

An excellent non-pharmacological treatment for the improvement of endothelial function is regular physical exercise, which slows down the aging processes of the arterial wall and increases NO production, due to the greater synthesis of (eNOS), justifying a chronic adaptation of the vasodilator system to high blood flow ${ }^{(20,7)}$. Kasapis et al. ${ }^{(21)}$ predict that the indicators of peripheral inflammation associated with endothelial dysfunction are reduced by regular physical activity, improving NO bioavailability and, later, endothelial function. Regular physical exercise counteracts oxidative stress, which is responsible for promoting atherosclerosis through the oxidation of LDL (low density cholesterol), in order to stimulate the macrophages to migrate from the circulation to the walls of the vessels, forming the lesions atherosclerotic. However, the exercise has antiatherogenic effect, as it combats oxidative stress through a positive regulation of antioxidants ${ }^{(22)}$.

According to the level of training of the individual, with advancement in training and the relationship of nitric oxide with vasodilatation of vessels, there is a decrease in cardiovascular risk due to adaptations of the system in question. The improvement in vascular function is not restricted only to vessels of trained musculature, but to all blood vessels in the body ${ }^{(6,7)}$. In contrast, in the study by Silva ${ }^{(7)}$, high intensity training, when compared to low intensity and control group, improved the functional capacity and the endothelium-dependent vasodilator response in a period of 6 weeks of exercise. In another study, Lewis et al. ${ }^{(24)}$ diagnosed that 60 minutes after an exercise lasting 30 minutes, blood flow was still elevated by $75 \%$. 
It was observed that in Da Veiga's study ${ }^{(6)}$, endothelial function did not show any evolution or decrease, however, when compared to the control group of the same study, the group of the water aerobics intervention presented greater sensitivity to nitric oxide, whereas in the control group there was a decrease in arterial diameter and, consequently, reduction in NO production. Regarding this, Silva ${ }^{(7)}$ affirms that individuals who do not present endothelial dysfunction do not obtain modifications in their vascular function. Following the same line as the above-mentioned author, Green et al. (26) point out that physical exercise seems to have little or no impact when endothelial function is normal. On the work of Bergholm et al. ${ }^{(27)}$, the authors explained that the decrease in endothelial function occurred due to the high intensity imposed on the training, which resulted in a decrease in the levels of antioxidants circulating in the blood.

On the prevalence of different types of breed, Feairheller et al. ${ }^{(28)}$ point out that according to the American Heart Association (AHA), African-Americans have a higher prevalence in cardiovascular diseases and greater oxidative stress and inflammation levels in endothelial cells compared to Caucasian individuals.

\section{CONSIDERATIONS}

According to the studies reviewed in this study, impaired endothelial function improves through aerobic training, whether low, moderate or high intensity. When comparing the protective effect of moderate to high intensity exercises on the blood vessels of rats, Kelly et al. ${ }^{(10)}$ revealed that both provided protection. Ciolac ${ }^{(29)}$ points out that physical exercise reduces the sympathetic tone of the smooth muscle cells in the arterial wall, either directly or through an increase in the sympathetic inhibitory effect of nitric oxide, which may be involved in the reduction of arterial stiffness and consequent improvement in endothelial function.

On the benefits of physical activity, Apor and Radi(20) say that this slows the processes of aging of the arterial wall and endothelial function, which can be noticed through examinations, such as the echographic check of the post-ischemic dilatation of the vessels.

\section{AUTHORS' CONTRIBUTION}

AGA, RLR and ALE: developed study design. AGA, RLR and AAS: manuscript preparation. AGA, EFG and DSB: manuscript revision.

\section{CONFLICTS OF INTEREST}

There was not interest conflicts.

\section{AUTHOR DETAILS}

${ }^{2}$ Universidade Nove de Julho (UNINOVE), São Paulo (SP), Brazil.

\section{REFERENCES}

1. Bahia L, Aguiar LGK, Villela NR, Bottino D, Bouskela G. O endotélio na Síndrome Metabólica. Arquivos Brasileiros de Endocrinologia. Metabólica. 2006;5(2):291-303.
2. Chisi G, LM, Durieux A, Pinho R, Benetti M. Exercício Físico e Disfunção Endotelial. [dissertation]. Santa Catarina: Universidade do Estado de Santa Catarina; 2010.

3. Lima DS, Miranda JR, Hatta F, Lima W, Sato E. Função endotelial: considerações metodológicas. Revista Brasileira de Reumatologia. 1998; 38:229-53.

4. Powers SK, Howley ET. Fisiologia do Exercício. São Paulo: Manole; 2005.

5. Anderson TJ. Assessment ant treatment of endhotelial dysfunctions in humans. J Am Coll Cardiol. 1999;34:631-8.

6. Da Veiga ADR. Efeitos do treinamento aeróbio, em hidroginástica, na reatividade vascular em homens obesos. Programa de pós-graduação da Universidade Federal do Rio Grande do Sul: Porto Alegre; 2008.

7. Silva CA. Treinamento aeróbio de alta intensidade melhora a vasodilatação dependente do endotélio em pacientes com síndrome metabólica ou diabetes mellitus tipo 2 [dissertation]. Rio Grande do Sul: Universidade Federal do Rio Grande do Sul; 2006.

8. Dias RG, Negrão CE, Krieger MH. Óxido nítrico e sistema cardiovascular: ativação celular, reatividade vascular e variante genética. Instituto do Coração - InCor (HCFMUSP). São Paulo: Unicamp; 2009.

9. Hamet $P$, Tremblay J. A genetic determinants of the stress response in cardiovascular disease. Metabolism. 2002;(51):15-24.

10. Kelly AS, Wetzsteon RJ, Kaiser DR, Steinberger J, Bank A, Dengel DR. Inflammation, insulin, and endothelial function in overweight children and adolescents: the role exercise. J Pediatr. 2004;145:731-6.

11. Cooke JP, Rossitch E, Andon NA, Loscalzo J, Dzau V. Flow activates an endhotelial potassium chanel to release an endogenous nitrovasodilator. J. Clin. Invest. 1991;88:1663-71

12. Luz PL, Uint L. O endotélio na aterosclerose: interações celulares e vasomotricidade. IN: Luz P, Laurindo F, Chagas ACP. Endotélio: Doenças cardiovasculares. São Paulo: Atheneu; 2005.

13. Thompson PD. O exercício e a Cardiologia do Esporte. São Paulo: Manole; 2004.

14. Cabral MD, Teixeira PFS, Leite SP, Vaisman M. Marcadores de função endotelial no hipotireoidismo. Arquivos Brasileiros de Endocrinologicos e Metab. 2009;53(3).

15. Gewaltig MT, Kodja G. Vasoprotection by Nitric Oxide: mechanisms and therapeutic potential. Cardiovasc Res. 2002;55(2):250-60.

16. Ozaki MR. Estudo do relaxamento dependente do endotélio em ratos submetidos a infarto experimental e tratados com inibidores da enzima conversora de angiotensina e bloqueadores específicos dos receptores AT1. São Paulo: Unicamp; 2001.

17. Zenere BM, Arcaro G, Saggiani F. Noninvasive detection of functional alterations of arterial wall in IDDM patients with microalbuminuria. Diabetes Care. 1995;18:975-82.

18. Mariorana A, O'Driscoll G, Cheetham C, Dembo L, Goodman C, Taylor $\mathrm{R}$, et al. Effect of aerobic and resistance exercise training on vascular function in heart failure. American Journal of Physiology. 2000;279:1999-2005.

19. Virdis A, Ghiadoni L, Versari D, Giannarelli C, Salvetti A, Taddei S. Endothelial function assessment in complicated hypertension. Curr Pharm Dês. 2008;14(18):1761-70.

20. Apor P, Radi A. Vascular effects of physical activity. Orvosi Hetilap, 2005;146(2):483-9.

21. Kasapis C, Thompson PD. The effects of Physical Activity on serum C-reative protein and inflammatory markers: a systematic review. J Am Coll Cardiol. 2005;45(10):1563-9.

22. Ross MD, Malone E, Florida-James G. Vascular Ageing and Exercise: Focus on Cellular Reparative Processes. Oxid Med Cell Longev. 2016.

23. Hornig B, Maier V, Drexler $\mathrm{H}$. Physical training improves endothelial function in patients with chronic heart failure. Circulation. 1996;93(2):210-14. 
24. Lewis TV, Dart AM, Chin-Dusting JPF, Kingwell BA. Exercise training increases basal nitric oxide production from the forearm in hypercholesterolemic patients. Arterioscler Thromb Vasc Biol. 1999;19:2782-7.

25. Goto C, Higashi Y, Kimura M, Noma K, Hara K, Nakagama K, et al. Effect of different intensities of exercise on endothelial-dependent vasodilatation in humans: role of endothelium-dependent nitric oxide and oxidative stress. Circulation. 2003;108:530-5.

26. Green DJ, Cable NT, Fox C, Rankin JM, Taylor RR. Modification of forearm resistance vessels by exercise training in young men. J. Appl. Physiol. 1994;(77):1829-33.
27. Bergholm R, Makimattila S, Valkonen M, Liu M, Lahdenperas S, Taskinen $M$, et al. Intense physical training decreases circulating antioxidants and endothelium-dependent vasodilatation in vivo. Atherosclerosis. 1999;145:341-9.

28. Feairheller DL, Diaz KM, Kashem MA, Thakkar SR, Veerabhadrapp $\mathrm{P}$, Sturgeon KM, et al. Effects of Moderate Aerobic Exercise Training on Vascular Health and Blood Pressure in African Americans. J Clin Hypertens. 2014; 16(7):504-10.

29. Ciolac EG. Efeito do exercício físico contínuo versus intervalado sobre a pressão arterial, rigidez arterial e qualidade de vida em pacientes hipertensos. Faculdade de Medicina da Universidade de São Paulo: São Paulo; 2006. 